\title{
COVID-19: Winter Is Coming
}

J Gen Intern Med 36(3):810

DOI: $10.1007 / \mathrm{s} 11606-020-06362-4$

(C) Society of General Internal Medicine 2021

$\mathrm{D}$ ear editor,

We read with great interest the study published by Bai and Zare. They evaluated the structure of hospital operating costs during the COVID-19 pandemic and demonstrated that cancelation of elective surgery and the decline of hospital visits caused by COVID-19 have resulted in hospitals losing revenue and being forced to reduce costs from these services. ${ }^{1} \mathrm{We}$ would like to point out additional impact the pandemic may have on the health system.

COVID-19 has already caused significant disruption to political, social, and health care systems. Many patients with COVID-19 presented with viral pneumonia, with prolonged ICU stays in approximately $5 \%$ of cases. ${ }^{2}$ This has resulted in near collapse for many health care systems. Social distancing was the main measure adopted by national governments. This has led to near collapse of many economies and, while necessary to reduce the infection rate, has contributed to many patients with other health conditions delaying or missing needed care. Thus, the pandemic will probably cost more lives xthan we currently attribute to it. For example, transplantations have decreased worldwide ${ }^{3}$ for a number of reasons including a lack of ICU beds and mechanical ventilators to support the potential donor pool, as well as a reduction in hospitalizations for other conditions that could have yielded organ donations. Consequently, there has been a rise in mortality among patients awaiting transplants. There has also been an increase in mortality among cancer patients, many of whom have delayed treatment, frightened by the possibility of becoming infected by SARS-CoV-2.

The downstream impact could be high. There will likely be an increase in urgent hospitalizations from cancer spread, as well as advanced liver disease, congestive heart failure, and other chronic diseases. These hospitalizations will be costly and will impact health care manpower needs. While many lives are being lost due to COVID-19, we must prepare for winter and the potential future loss in life that may be coming.

Anderson Brito-Azevedo, $\mathrm{MD}, \mathrm{MSc}^{1,2}$

Fernanda Ciuffo Monte da Costa, $M D^{3}$

${ }^{1}$ Liver Transplant Unit, São Lucas Hospital, Rio de Janeiro, RJ, Brazil

${ }^{2}$ Liver Transplant Unit, Adventista Silvestre Hospital, Rio de Janeiro, RJ, Brazil

${ }^{3}$ Pediatric Intensive Care Unit, Quinta D'or Hospital, Rio de Janeiro, RJ, Brazil

Corresponding Author: Anderson Brito-Azevedo, MD, MSc; Liver Transplant Unit, Adventista Silvestre Hospital, Rio de Janeiro, RJ, Brazil (e-mail: andersonbrito.a@gmail.com).

\section{Compliance with Ethical Standards:}

Conflict of Interest: The authors declare that they do not have a conflict of interest.

\section{REFERENCES}

1. Bai G, Zare H. Hospital Cost Structure and the Implications on Cost Management During COVID-19. J Gen Intern Med. 2020. https://doi.org/ 10.1007/s11606-020-05996-8.

2. Murthy S, Gomersall CD, Fowler RA. Care for Critically Ill Patients With COVID-19. JAMA. 2020. https://doi.org/10.1001/jama.2020.3633

3. Maggi U, De Carlis L, Yiu D, et al. The Impact of the COVID-19 Outbreak on Liver Transplantation Programs in Northern Italy. Am J Transplant. 2020. https://doi.org/10.1111/ajt.15948.

Publisher's Note: Springer Nature remains neutral with regard to jurisdictional claims in published maps and institutional affiliations. 